\title{
Smaller is better: Associations between personality and demographics are improved by examining narrower traits and regions
}

\author{
Lorien G. Elleman ${ }^{1 *}$, David M. Condon ${ }^{2}$, Nicholas S. Holtzman ${ }^{3}$, Victoria R. Allen ${ }^{4}$, and William \\ Revelle $^{1}$
}

1. Department of Psychology, Northwestern University, Evanston, Illinois. 2. Department of Medical Social Sciences, Northwestern University, Chicago, Illinois. 3. Psychology Department, Georgia Southern University. 4. Children's Healthcare of Atlanta. *Corresponding author: LorienElleman@gmail.com.

\begin{abstract}
The personality of individuals is clustered by geographic regions; a resident of a region is more similar to another resident than to a random non-resident. Research in geographical psychology often has focused on this clustering effect in broad regions, such as countries and states, using broad domains of personality, such as the Big Five. We examined the extent to which (a) a narrower geographic unit, the U.S. ZIP Code, accounted for more variance explained in aggregating personality than a broader region, the U.S. state; and (b) progressively narrower personality traits (domains, facets, and nuances, respectively) provided more specificity in describing personality-demographic relationships. Results from this study $\left(n_{\text {participants }}=39,886, n_{\text {zipcodes }}=2,074\right)$ indicated that the variance explained by aggregating personality was multiple times as large for U.S. ZIP Codes than for states (median = 4.4). At the level of personality domains, ZIP Code population density and income disparity were positively correlated with Openness and negatively correlated with Conscientiousness and Agreeableness. Facets within each domain were differentially correlated with each demographic, which demonstrated that facets added specificity to the personality-demographic relationships beyond that of domains. Item-level analysis revealed the most specific finding: higher population density and income disparity were associated with politically liberal attitudes and beliefs of self-exceptionalism, while lower density and income disparity were associated with authoritarian attitudes and concern for abiding by rules and laws. Findings suggest that future studies in
\end{abstract}


geographical and personality psychology could benefit from using the narrowest feasible unit of analysis.

Keywords

geographical psychology; Big Five; domain; facet; nuance; U.S. state; ZIP Code

\section{Introduction}

Over the last two decades, findings in geographical psychology have suggested that the personalities of individuals are clustered by geographic regions (Rentfrow \& Jokela, 2016). That is, a resident of a region typically has a more similar personality to fellow residents than non-residents. Additionally, the aggregated personalities of regions are associated with important region-level demographics, such as rates of chronic disease (Pesta, Bertsch, McDaniel, Mahoney, \& Poznanski, 2012) and crime (Rentfrow, Gosling, \& Potter, 2008). These results have been found for regions of varying sizes: countries (McCrae \& Terracciano, 2008), large regions within a country (e.g., New England and the Midwest; Rentfrow, Gosling, Jokela, \& Stillwell, 2013), smaller regions within a country (e.g., U.S. states; Rentfrow et al., 2008), cities (Park \& Peterson, 2010), and even neighborhoods within a city (Jokela, Bleidorn, Lamb, Gosling, \& Rentfrow, 2015).

There are at least three theories regarding why personality is aggregated by geographic regions and why regions' personalities are correlated with their demographics (for a full review, see Rentfrow et al., 2008). First, environmental factors may shape residents' thoughts, feelings, behaviors, and beliefs in consistent ways. For example, a neighborhood's income inequality may influence its residents' risk-taking behavior, with greater inequality causing riskier behavior (Kawachi, Kennedy, Lochner, \& Prothrow-Stith, 1997; Wilson \& Daly, 1997; Payne, 2017). Second, similar individuals may migrate to the same region due to opportunities there. For instance, because cities, compared to small towns, create more opportunities for hedonistic and faster-paced lifestyles, they may also attract individuals who exhibit more antisocial personality traits (Jonason, 2018). A third theory posits that social influence may also play a role; social interactions with personality-typical residents may persuade new residents toward the prevailing beliefs and attitudes of the region (Rentfrow et al., 2008; Rentfrow, 2010). 
The typical method of aggregating individual personality scores into regional scores is to calculate a mean personality score for each region. Total personality variance is composed of withinregion variance (how much individual personalities vary within a region) and between-region variance (how much aggregated regional personalities vary). The amount of total variance explained by regional residence is expressed as a ratio of between-region variance over total variance (Bliese, 2000). Most geographical psychology studies have not reported this ratio, but a recent replication study found that across seven samples, U.S. state residence accounted for $0.3 \%$ of individual variance of Big Five personality, a small but reliable effect (Elleman, Condon, Russin, \& Revelle, 2018).

\section{U.S. ZIP Codes may better aggregate personality than states}

Regions as large as U.S. states may account for such a small percentage of personality variance because each region does not contain an especially homogeneous population. A state can encompass millions of people who are spread out over tens of thousands of square miles. Residents of the same state can live in dissimilar environments, such as a quiet, sparsely inhabited countryside and a bustling, crowded metropolis. These environmental differences are associated with individual differences of residents. For example, despite states often being represented as either "red" or "blue," residents of a state vary in their political affiliations (Seyle \& Newman, 2006), and voting patterns are clustered by urban density (with some exceptions; Morrill, Knopp, \& Brown, 2007). Additionally, compared to residents of smaller cities, residents of bigger cities in the U.S. tend to have higher levels of education and income (Glaeser \& Maré, 2001), and different occupational skills (Bacolod, Blum, \& Strange, 2009). Even within a city, the population density of a neighborhood is associated with differences in neighborhood personality (Jokela et al., 2015).

Compared to state-sized regions, U.S. ZIP Codes may better cluster individuals' personalities because the environment of a ZIP Code is smaller and more uniform than an entire state. Individuals with similar personalities may cluster together in a ZIP Code because they face similar economic constraints or have similar desires for the amenities of the ZIP Code. There is evidence of this clustering for neighborhoods, geographic areas that are typically smaller than U.S. ZIP Codes. People prefer to live in neighborhoods where other residents are of similar political affiliations 
(Gimpel \& Hui, 2015) and ideologies (Motyl, Iyer, Oishi, Trawalter, \& Nosek, 2014). Additionally, liberals and conservatives differentially prefer certain aspects of neighborhoods, such as nearness to museums, ethnic diversity, and religious homogeneity (Pew Research Center, 2014). Besides political affiliation, a person may be more likely to migrate to a neighborhood in which the person's self-image closely matches the perceived typical resident (Sirgy, Grzeskowiak, \& Su, 2005). The benefits of this type of person-environment fit have been found at the city level: a better fit between the aggregated personality of a city and a city's resident is associated with higher self-esteem of the resident (Bleidorn et al., 2016). Additionally, characteristics of a neighborhood, such as its affluence or ethnic diversity, impact the individual differences of resident children and adolescents, such as their cognitive ability and behavioral problems (for a review, see Leventhal \& Brooks-Gunn, 2000).

\section{Narrow personality traits may be more informative than broad traits}

The dominant trait model of personality psychology is the "Big Five" taxonomy, which is composed of five broad domains (Openness, Conscientiousness, Extraversion, Agreeableness, and Neuroticism; Goldberg, 1999). An abundance of studies correlating Big Five domains with life outcomes has helped the Big Five to become widely accepted personality constructs (for reviews, see Ozer \& Benet-Martínez, 2006 and Roberts, Kuncel, Shiner, Caspi, \& Goldberg, 2007).

A limitation of the Big Five is their broad nature. Facets, narrower traits nested within domains, often account for more outcome variance than Big Five domains and provide greater specificity to personality-outcome relationships (Paunonen \& Ashton, 2001; Mershon \& Gorsuch, 1988). Across multiple cultures, narrower traits have predicted more replicated behavioral outcomes than the Big Five (Paunonen, Haddock, Forsterling, \& Keinonen, 2003). Additionally, personality-outcome relationships that appear to exist at the domain level may in fact be driven by facets. For example, Mõttus and colleagues (2012) found that the likelihood of sexually transmitted disease (STD) diagnosis was related to two of the Big Five domains (Neuroticism and Agreeableness) but only three of thirty personality facets (Impulsivity, Hostility, and Deliberation). At the aggregated level of U.S. states, facets of Extraversion (Assertiveness and Activity) have been found to be differentially correlated with state-level demographics (Rentfrow, 2014).

Personality researchers have recently delved into even narrower traits, or "nuances," which are 
the breadth of individual items (McCrae, 2015). Concerns about the low reliability of items have been answered with large-sample studies indicating that nuances are reliable and valid constructs; the unique variance of individual items has cross-rater agreement, is rank-order stable, and is partially heritable (Mõttus, McCrae, Allik, \& Realo, 2014; Mõttus, Kandler, Bleidorn, Riemann, \& McCrae, 2017; Mõttus, Sinick, et al., 2018). Growing evidence suggests that nuance-level models provide more specificity and predictive power than models that utilize facets or domains (Seeboth \& Mõttus, 2018; Mõttus et al., 2015; Mõttus, Bates, Condon, Mroczek, \& Revelle, 2018; Elleman, Condon, McDougald, \& Revelle, in press; Revelle, Dworak, \& Condon, 2020). This additional specificity can alter how findings are interpreted. For example, body mass index has been found to be positively correlated with the facet Impulsivity across several studies, but this relationship appears to be more accurately attributed to just two eating-related Impulsivity items (Terracciano et al., 2009; Vainik, Mõttus, Allik, Esko, \& Realo, 2015). Another study found that, across 40 outcomes, the specific variance of nuances accounted for a substantial portion of the predictive power of domain-level models, suggesting that the idiosyncrasies of individual items are more responsible for domain-level relationships than is commonly understood (Seeboth \& Mõttus, 2018). Lastly, one recent study found that a participant's country of origin was better predicted with personality items than facets or domains (Achaa-Amankwaa, Olaru, \& Schroeders, 2020). Taken together, this body of research indicates that examining personality-outcome relationships at a level higher than nuances "entails a substantial loss of information" (Mõttus et al., 2015, p. 25) and risks misattributing nuance-level personality-outcome relationships to broader traits.

\section{Overview of the current study}

We had two primary aims. The first was to estimate the variance explained by aggregating personality for U.S. ZIP Codes and states. Because the environment of a ZIP Code should be smaller and more homogeneous than a state, we predicted that the aggregation effect for U.S. ZIP Code residence would be larger than for U.S. state residence. The study's second aim was to determine whether greater specificity (i.e., a more specific relationship that could not be attributable to a broader trait) could be gleaned from geographical psychology findings with the use of progressively narrower personality traits (domains, facets, and nuances, respectively). First, we found the zero- 
order correlations between ZIP Code demographics and aggregated Big Five domains. We then investigated whether facets within a domain were differentially correlated with the demographic. To determine personality-demographic relationships at the nuance level, we first found the personality items that were most highly correlated with each demographic. For each demographic, we created a scale composed of these best items (a "best-items scale"). This type of scale has also been referred to as a "polyitem score" (Mõttus, Bates, et al., 2018) and is similar to the dustbowl empiricism of the Minnesota Multiphasic Personality Inventory (Hathaway \& McKinley, 1942). Lastly, we compared the effect sizes of regression models using domains, facets, and nuances in order to determine if greater specificity was a benefit or detriment to prediction.

\section{Methods}

\section{ZIP Code definition}

ZIP Code residence was self-reported by participants. ZIP Codes were matched to ZIP Code Tabulation Areas (ZCTAs), areal approximations of U.S. ZIP Codes (Alabama State Data Center, 2015), using a "crosswalk" table that linked every ZIP Code to a ZCTA (American Academy of Family Physicians, 2017). Matching ZIP Codes to ZCTAs was necessary in order to link participant data to U.S. Census demographic data, which were reported at the ZCTA level. In some cases, multiple ZIP Codes were contained within one ZCTA. At the time of the current study, there were approximately 33,000 ZCTAs (Alabama State Data Center, 2017) and 42,000 ZIP Codes (U.S. Postal Service, 2017) in the U.S.

\section{Participants}

Screening procedures. Participant data were collected from the Synthetic Aperture Personality Assessment (SAPA) project, an international online personality assessment (https://SAPA -project.org; Revelle et al., 2016). As compensation for taking the survey, participants received automated feedback concerning their personality. Participant data for this sample were collected from January 2013 to February 2017 and are publicly available (Condon \& Revelle, 2018, 2015a; 
Condon, Roney, \& Revelle, 2017c,b). ${ }^{1}$ To limit the sample to those living in the U.S. who, more likely than not, had a choice concerning where they resided, we included participants only if they provided a valid U.S. ZIP Code of their residence and indicated they were 18 years of age or older. Participants were excluded if they were 18 years old and indicated they had not finished high school, due to our assumption that they would still be residing in their parents' home (i.e., they did not yet have the choice concerning where to reside). As was standard lab practice, we removed participants who reported having previously taken the assessment and duplicate entries taken in the same internet browser session. Based on these initial criteria, there were 75,716 participants in 14,000 unique ZIP Codes, with a mean of 5.4 participants per ZIP Code (median $=3$ ). The distribution of participants per ZIP Code was positively skewed, with 6,612 ZIP Codes containing one or two participants. To lower the error associated with aggregated personality estimates of ZIP Codes, ZIP Codes were excluded if they contained less than 10 participants, as this cutoff improved the reliabilities of ZIP Code measures while retaining a large number of participants and ZIP Codes. ${ }^{2}$ This requirement reduced the sample to 39,886 participants in 2,074 ZIP Codes (Figure 1) and increased the mean number of participants per ZIP Code to 19.2 (median $=14$ ). This final sample had a younger median age, 24 years, compared to the initial sample, 25 years. Other descriptive information regarding differences in the initial and final samples are available in Table 1 of the supplemental materials.

Participant demographic information. For the final sample that required at least 10 participants per ZIP Code, median self-reported age was 24 years (median absolute deviation $=7$ ), with a range from 18 to 89 years. Female participants accounted for $65 \%$ of the sample. Of the $80 \%$ of participants who reported their ethnicity, $62 \%$ identified themselves as White, $13 \%$ as Hispanic American, 12\% as African American, 5\% as Asian American, 1\% as Native Alaskan/Hawaiian/ American, and $8 \%$ as multi-racial or "other." Percent of minority participants in each ZIP Code was calculated by dividing the number of participants in a ZIP Code who indicated any ethnicity besides "White" by the number of participants in a ZIP Code who self-reported their ethnicity.

\footnotetext{
${ }^{1}$ Participant ZIP Code data have not been publicly shared but are available to researchers upon request. Additionally, the cited data sets are from 2010 to 2017, but SAPA began collecting ZIP Code information in 2013.

${ }^{2}$ See Tables 1, 2, and 3 of the supplemental materials for analyses related to different minimums of participants per ZIP Code.
} 
Figure 1. : Map of 2,074 U.S. ZIP Codes in which 39,886 participants reside. Each ZIP Code contains at least ten participants $($ mean $=19.2)$. Larger dots indicate more participants in a ZIP Code. ZIP Codes in Alaska and Hawaii (totaling five) are not shown.

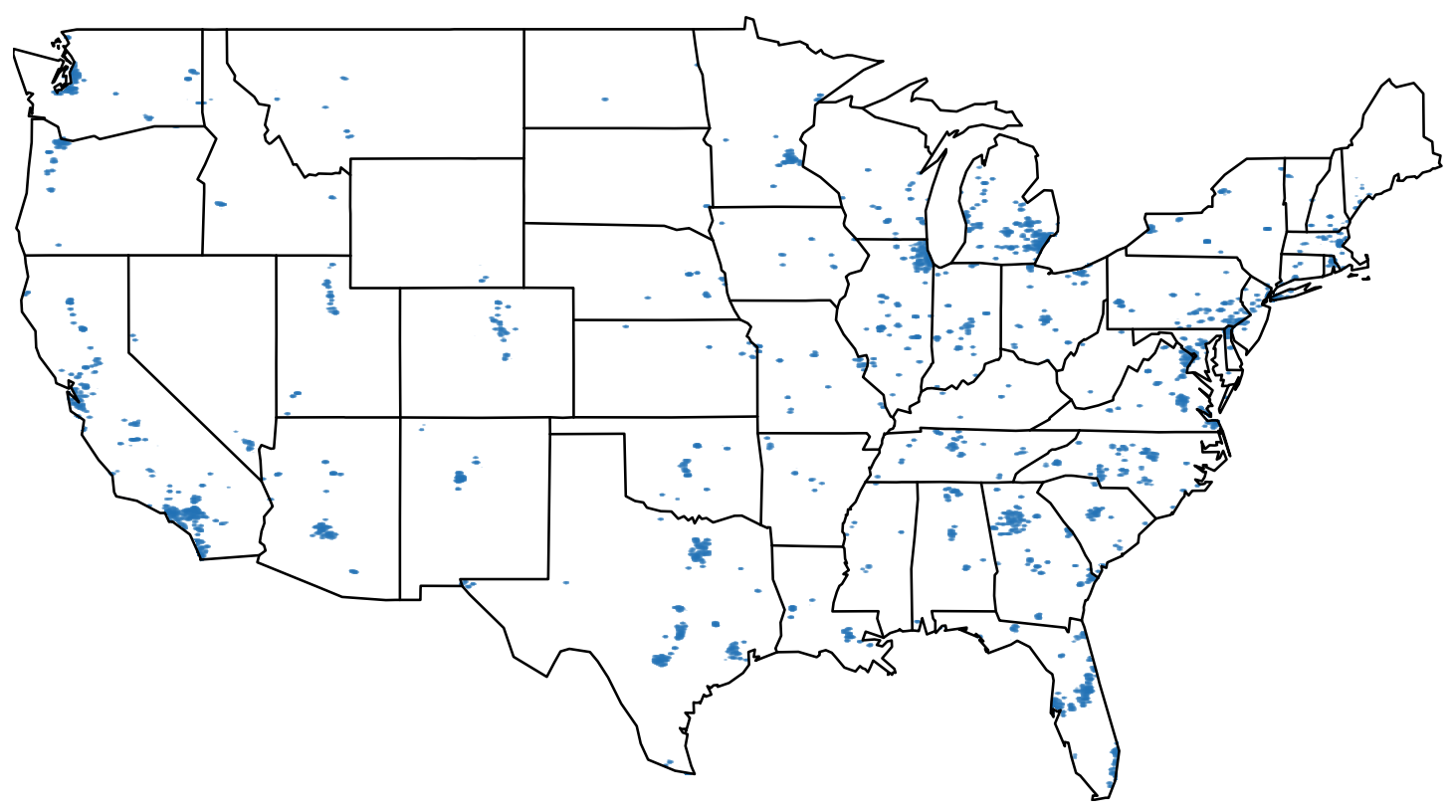

The percent of minority participants in ZIP Codes had a large correlation $(r=.66, p<.001)$ with the Census estimate of percent of minority residents in each ZIP Code, which indicated minority representativeness in ZIP Codes for this study's sample.

Participants self-reported their educational attainment and their parents' educational attainment, using a scale with seven options, ranging from "Less than 12 years" to "Graduate or professional school degree." Almost all participants provided their own education (97\%) and at least one parent's education $(91 \%){ }^{3}$ College students accounted for $57 \%$ of the sample that reported their education, while $30 \%$ reported having at least a bachelor's degree. Of the participants who responded, $52 \%$ reported that at least one of their parents had attained at least a bachelor's degree.

Personality measures. Unlike most personality assessments, the SAPA project does not require that a participant answer every item from every scale. The SAPA project utilizes a massively-

\footnotetext{
${ }^{3}$ In instances of both parents' educational attainment being reported, an average of the two was taken so that one variable could represent mean parents' education. Although education categories were not technically intervals, each more advanced education category was approximately equivalent to two additional years of schooling.
} 
missing-completely-at-random (MMCAR) procedure in which participants receive randomly selected items from each inventory of interest (Revelle, Wilt, \& Rosenthal, 2010; Revelle et al., 2016). Items from each inventory may have a different sampling rate. Due to high rates of missingness, missing scores were not imputed; aggregated personality scores for ZIP Codes and all analyses were trained only on non-missing item scores. Although imputation can allow for unbiased estimates of missing data (Little, Jorgensen, Lang, \& Moore, 2013), a recent study of SAPA data with $90 \%$ data missingness indicated that models based on imputed data were less predictive than models trained only on the $10 \%$ actual data (Elleman et al., in press).

For all personality items, participants rated themselves using a six-point Likert-like scale $(1=$ "very inaccurate," 6 = "very accurate"). Big Five domains and facets were measured with items sampled from the 300-item IPIP-NEO inventory from the International Personality Item Pool (IPIP; http://ipip.ori.org/), an online repository for public domain items and scales (Goldberg, 1999; Goldberg et al., 2006). Each of the IPIP-NEO Big Five domains consisted of six facets and 60 items; each of the 30 IPIP-NEO facets consisted of ten items. The IPIP-NEO Big Five domains and facets are based on the NEO-PI-R conception of the Big Five (Costa \& McCrae, 1992). On average, each participant was given 30 Big Five items (10\% of the inventory). For item-level analyses, 696 items from 92 public-domain personality scales were used (Condon \& Revelle, 2015b; Condon, Roney, \& Revelle, 2017a), which included the 300 IPIP-NEO items.

\section{ZIP Code demographic measures}

Four demographics of interest were selected: population density, income disparity, ${ }^{4}$ median income, and ethnic diversity. Three of the four demographics (population density, income disparity, and ethnic diversity) were chosen due to previous evidence in the literature that indicated these demographics were correlated with personality at geographic levels smaller than countries (Jokela

\footnotetext{
${ }^{4}$ Of the four demographics, readers may be the least familiar with income disparity. Income disparity refers to the extent to which income is distributed unevenly among residents in a ZIP Code (see Methods for more detail on the calculation). Income disparity is not synonymous with median income; the median income of more income disparate ZIP Codes may be lower than the national median (e.g., Pittsburgh, PA, 15213) or higher (e.g., New York, NY, 10013). Conversely, there may be less income disparity in a ZIP Code when residents tend to earn less than the national median (e.g., Killeen, TX, 76544; near Fort Hood) or more (e.g., Ashburn, VA, 20147; a suburb of Washington, DC). Compared to equal-income areas, income disparate areas tend to have higher rates of crime (Wilson \& Daly, 1997; Daly, Wilson, \& Vasdev, 2001; Rufrancos, Power, Pickett, \& Wilkinson, 2013), worse economic outcomes for individuals (Frank, 2013) and lower life expectancy (Pickett \& Wilkinson, 2015).
} 
et al., 2015; Jokela, 2014; Glaeser \& Maré, 2001; Tausanovitch \& Warshaw, 2014; Pew Research Center, 2014). Median income was chosen as an exploratory variable and a contrast to income disparity. All four ZIP Code-level demographics were chosen in part because they were variables of convenience; they were publicly available from the U.S. Census Bureau.

Population density and ethnic household data were taken from the 2010 Census (Alabama State Data Center, 2012). Income data were taken from the 2013 American Community Survey (U.S. Census Bureau, 2017). Ethnic diversity was calculated using an "index of fractionalization" formula, which is the probability that two randomly selected residents of a ZIP Code would be of different ethnicities (Easterly \& Levine, 1997). For the final sample, the average ZIP Code ethnic diversity was $.36(\mathrm{SD}=.17)$. Income disparity was measured with the Gini index, as reported in the 2013 American Community Survey. The Gini index is a coefficient with a range from 0 to 1 that measures the distribution of incomes among a group of people (Ceriani \& Verme, 2011). In the context of this study, a ZIP Code with a Gini of 0 would indicate that income was distributed equally among residents of the ZIP Code, while a Gini of 1 would indicate that one resident accounted for all the income of the ZIP Code. For the final sample, the average ZIP Code Gini was .45 (SD = .06); for comparison, the World Bank's (2016) estimate of U.S. national Gini is .41.

\section{Statistical analyses}

All analyses were performed in RStudio (RStudio Team, 2020), an integrated development environment for the programming language $\mathrm{R}$ (R Core Team, 2018), using, most notably, the packages "psych" (Revelle, 2020) and "ggplot2" (Wickham, 2016). All analyses were at the aggregated ZIP Code level unless otherwise noted. ZIP Code-level scores of individual-level scales and items were calculated by taking the mean of individual scores for each ZIP Code that contained at least 10 participants. Significance testing of ZIP Code-level analyses was based upon the number of ZIP Codes included in the final sample $\left(n_{\text {zipcodes }}=2,074\right)$ unless otherwise noted. Median income and population density were natural-log-transformed for correlation and regression analyses due to each variable's positive skewness. 
Results

The magnitude and reliability of personality differences at the U.S. ZIP Code and state levels

To estimate the personality variance explained by ZIP Code and U.S. state residence, we calculated intraclass correlations (ICCs). ICCs partition total variance into within-group and betweengroup variance and reflect various ratio terms. Specifically, ICC1 indicates how much total variation is explained by aggregation (i.e., what percent of total variance is accounted for by ZIP Code residence; Shrout \& Fleiss, 1979). For all 35 personality variables of interest, the ZIP Code aggregation effect had a larger point estimate than the state aggregation effect (Figure 2). ${ }^{5}$ A paired t-test indicated that there was a significant difference in the percent of personality variance explained by ZIP Codes $(M=2.6, S D=3.9)$ and states $(M=0.6, S D=1.0) ; t(34)=7.25, p<.001$. Based on the median ratio, the ZIP Code aggregation effect for personality was 4.4 times as large as the effect for U.S. states. The personality variance explained by ZIP Code residence had a range from $1.0-1.4 \%$ for the Big Five domains and $0.2-7.0 \%$ for the 30 personality facets. ${ }^{6}$

ICC2 measures group mean reliability and estimates the extent to which one would expect aggregated differences (i.e., aggregated ZIP Code personality differences) to replicate in a new sample of a similar size (Bliese, 2000). ICC2 values have a range from 0 to 1 . Similar to the Spearman-Brown prophecy formula, as the average number of participants per group (ZIP Code) increases, even a small aggregated effect (ICC1) can have a reliable group mean difference (ICC2). Because ICC2 values are determined by the number of participants in a group and the magnitude of ICC1 values, ICC2 reliabilities were not large for Big Five domains (range: .16-.44) or facets (range: .02-.40; Table 3 of the supplemental materials). ${ }^{7}$

\footnotetext{
${ }^{5}$ To determine if the personality variance explained by ZIP Code residence would still be consistently larger than that of states, even if the data were random, a simulation (1,000 iterations) was run such that participants were randomly assigned to ZIP Codes and states. In the simulation, the personality variance explained was less than $0.01 \%$ for ZIP Codes and states, and ZIP Code ICC1s had a larger point estimate than state ICC1s for 20 of the 35 variables $(57 \%)$.

${ }^{6}$ To ensure that ICC1 values were not due to the minimum of 10 participants per ZIP Code, we compared ICC1 values across four minimums (5, 10, 15, and 20 participants per ZIP Code). ICC1 values for personality variables were stable across the four minimums (Table 2 of the supplemental materials).

${ }^{7}$ ICC2 reliabilities were consistently improved by increasing the required minimum number of participants per ZIP Code (Table 3 of the supplemental materials).
} 
Figure 2. : Percent of total variance explained by ZIP Code and U.S. state residence (ICC1), with 95\% confidence intervals (unadjusted for multiple comparisons).

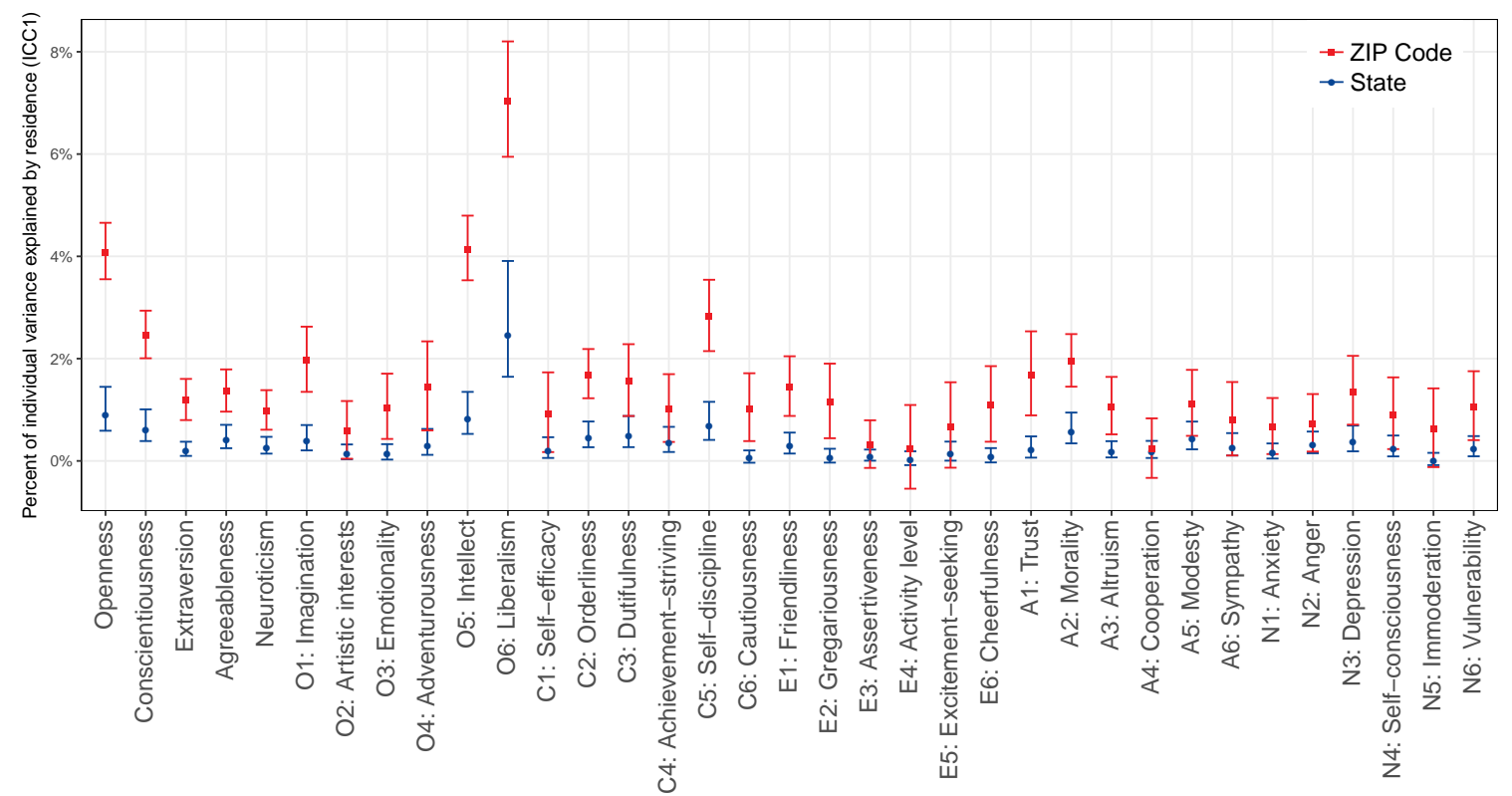

Zero-order correlations between ZIP Code demographics and aggregated participant Big Five personality

Zero-order correlations at the aggregated ZIP Code level were found for the four ZIP Code demographics and participants' Big Five domain scores. Because scores from ZIP Codes with more participants were more accurate estimates than ZIP Codes with fewer participants, correlations were weighted by the number of participants in a ZIP Code. To adjust for multiple comparisons, a Holm adjustment (Holm, 1979) was used to account for all 36 correlations. With the adjustment, the required minimum absolute correlation for typical statistical significance $(p<.05)$ was still very small $(|r|=.06)$. In order to focus on effects of a larger magnitude, the effect size threshold for a notable correlation was set to $|r|=.15\left(p<5 \times 10^{-10}\right)$. Based on this criterion, there were six notable correlations: population density was positively correlated with Openness $(r=.28)$, and negatively correlated with Conscientiousness $(r=-.17)$ and Agreeableness $(r=-.21)$; and income disparity was positively correlated with Openness $(r=.31)$, and negatively correlated with 
Conscientiousness $(r=-.23)$ and Agreeableness $(r=-.19$; Table 1; see Table 4 of the supplemental materials for a correlation matrix that includes participant demographics).

Table 1: Zero-order correlations between ZIP Code demographics and aggregated participant personality, weighted by the number of participants in each of the 2,074 ZIP Codes. Correlations with an absolute value greater than or equal to .06 are statistically significant $(p<.05)$. Notable correlations between U.S. Census demographics and aggregated participant variables are shown in bolded text.

\begin{tabular}{|c|c|c|c|c|c|c|c|c|c|}
\hline Data source & Variable & Pop. & Inc. & Med. & Eth. & Ope. & Con. & Ext. & Agr. \\
\hline \multirow{4}{*}{ U.S. Census } & Population density & & & & & & & & \\
\hline & Income disparity & .24 & & & & & & & \\
\hline & Median income & .06 & -.22 & & & & & & \\
\hline & Ethnic diversity & 41 & -.01 & -.17 & & & & & \\
\hline \multirow{5}{*}{ Participants } & Openness & .28 & .31 & .08 & .05 & & & & \\
\hline & Conscientiousness & -.17 & -.23 & -.11 & .03 & -.22 & & & \\
\hline & Extraversion & -.05 & -.07 & .03 & -.04 & -.01 & .15 & & \\
\hline & Agreeableness & -.21 & -.19 & -.03 & -.08 & -.08 & .27 & .13 & \\
\hline & Neuroticism & .02 & .07 & .00 & -.09 & .00 & -.24 & -.24 & -.14 \\
\hline
\end{tabular}

The robustness of the basic correlational structure. To ensure these zero-order correlational results were not an artifact of the requirement of 10 participants per ZIP Code, the robustness of the pattern of correlations was tested using a minimum of 5, 10, 15, and 20 participants per ZIP Code. For aggregated participant variables, a similar pattern of correlations emerged for all four minimums, although the absolute value of correlations typically increased as the minimum number of participants increased (Figures 1-4 of the supplemental materials). That is, the structure of the correlation matrix was largely the same, regardless of minimum participants per ZIP Code, but improved ICC2 reliabilities resulted in more accurate estimates of aggregated ZIP Code traits and thus larger absolute correlations between participant variables. Correlations between ZIP Code-level variables from the Census Bureau were mostly unchanged, regardless of the number of participants per ZIP Code.

Zero-order correlations between ZIP Code demographics and aggregated personality facets

Because population density and income disparity were found to be correlated with three of the Big Five (Openness, Conscientiousness, and Agreeableness), we examined whether facets within 
each of these domains were differentially correlated with population density (Figure 3) and income disparity (Figure 4). Facets of traits visually appeared to be differentially correlated with population density and income disparity, which prompted the statistical analyses of these potential differences.

Figure 3. : Correlations (and 95\% confidence intervals, unadjusted for multiple comparisons) of ZIP Code population density with aggregated personality of participants. Large shapes indicate domains. Small shapes indicate facets.

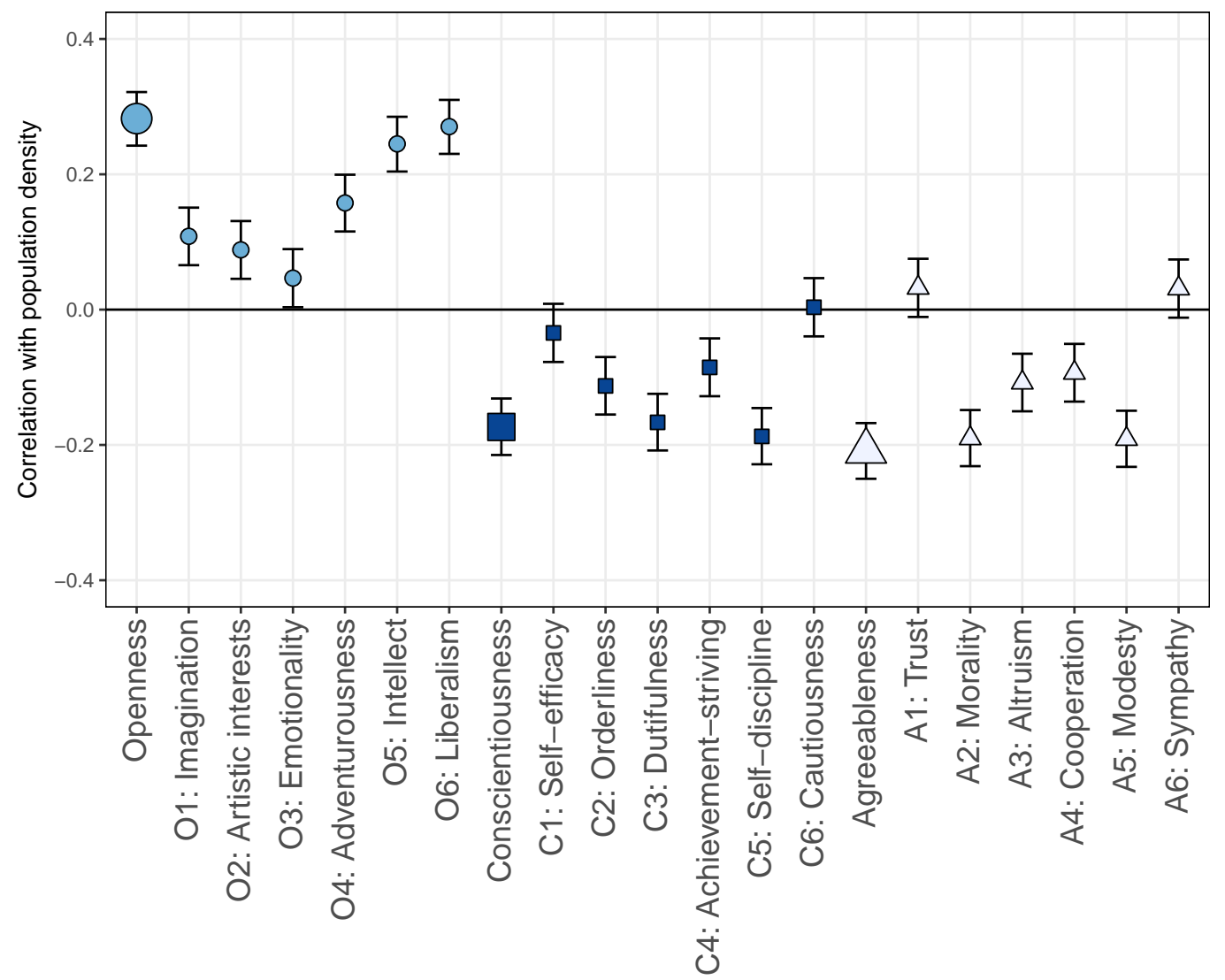

In order to determine which facets within a domain were most highly correlated with each demographic, the following approach was taken: First, for each domain, the facet with the largest absolute correlation with a demographic was identified (e.g., for Openness and population density, the Liberalism facet had the largest absolute correlation). Then, five tests determining the differences in non-independent correlations (Steiger, 1980) were performed to compare that demographic- 
Figure 4. : Correlations (and 95\% confidence intervals, unadjusted for multiple comparisons) of ZIP Code income disparity with aggregated personality of participants. Large shapes indicate domains. Small shapes indicate facets.

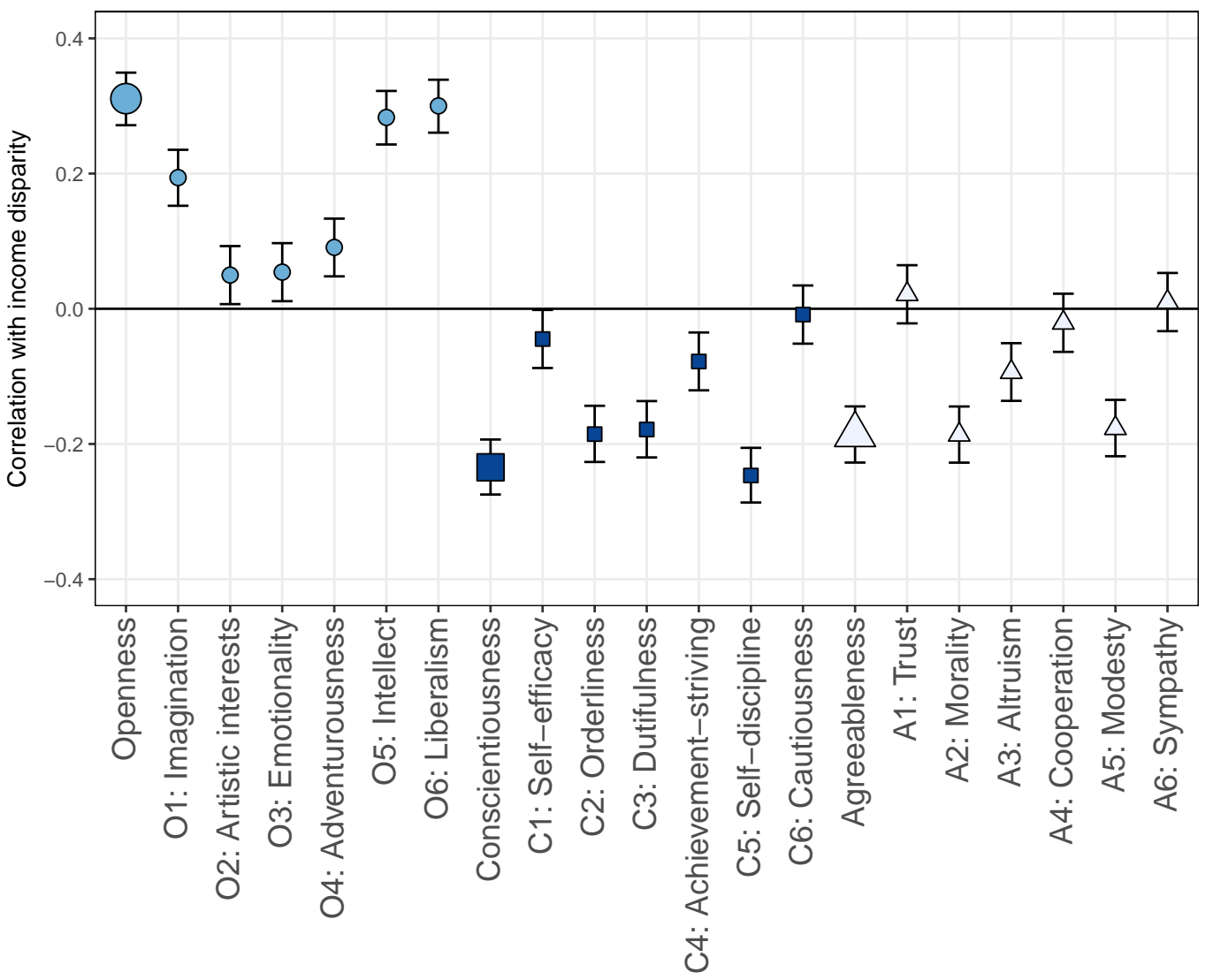

facet correlation with each other same-domain demographic-facet correlation (e.g., the population density-Liberalism correlation was compared against the correlations of the other five facets of Openness and population density). P-values were Holm-adjusted for the 30 comparisons. For the correlations with population density and the three relevant Big Five traits, six of eighteen facets were most responsible: Liberalism and Intellect (Openness); Self-discipline and Dutifulness (a facet of Conscientiousness); and Modesty and Morality (Agreeableness; Table 5 of the supplemental materials). For the correlations with income disparity and the three relevant Big Five traits, an almost identical list of seven facets was found, adding Orderliness (Conscientiousness; Table 5 of 
the supplemental materials).

Because facets within a domain could have been differentially correlated with a demographic such that the opposing effects would have cancelled each other out at the level of the domain, we also found facet-level correlations for all domains that were not meaningfully correlated with a ZIP Code demographic: facets of Extraversion and Neuroticism with population density (Figure 5 of the supplemental materials) and income disparity (Figure 6 of the supplemental materials), as well as all 30 facets with median income (Figure 7 of the supplemental materials) and ethnic diversity (Figure 8 of the supplemental materials). None of these correlations reached the threshold for a notable effect size $(|r|=.15)$.

\section{Zero-order correlations between ZIP Code demographics and aggregated personality nuances}

In order to gain even greater specificity in the relationship between the four ZIP Code demographics and aggregated personality, we correlated each demographic with all 696 personality items. To lower the likelihood of false-positive findings, we took an iterative approach that was similar to k-fold cross-validation (Chapman, Weiss, \& Duberstein, 2016) and bootstrap aggregation ("bagging"; Breiman, 1996). In each iteration, we found correlations for a random $90 \%$ training sample and $10 \%$ validation sample. For the training sample, we selected up to 34 personality items (5\% of the item pool) with the largest correlations with each demographic. We discarded correlations smaller than $|r|=.11$, which reflected the Bonferroni-adjusted (Dunn, 1961) minimum absolute correlation for standard statistical significance $(p<.05)$ based upon 696 comparisons and the minimum number of ZIP Code scores across the 696 items $\left(n_{\text {zipcodes }}=1,394\right)$. We found a multiple correlation for each demographic and the selected items for the training and validation samples. This process was iterated 1,000 times. We found and compared averages for training and validation multiple correlations. Then, for each demographic, we selected a final set of personality items, which was based upon having been in the top 34 items in at least $99 \%$ of the iterations. We combined each final set of items into a best-items scale and found the correlation between the scale and the corresponding demographic for the full sample. Lastly, we qualitatively assessed the item content in each best-items scale (which assumed the face validity of each item's content) to determine if there were consistent themes across the items. 
Table 2: The 21 personality items most highly correlated with ZIP Code population density. The column "Corr." is a mean of 1,000 zero-order correlations, each using a 90\% sample. Lower and upper confidence intervals are \pm 2 SDs based upon the 1,000 iterations. The column "Key" indicates whether the item was positively or negatively keyed on the listed domain/facet. Some items may appear in more than one inventory.

\begin{tabular}{|c|c|c|c|c|c|c|}
\hline Personality item & Corr. & Lower & Upper & Inventory & Domain/Facet* & Key \\
\hline Tend to vote for conservative political candidates. & -.22 & -.24 & -.21 & IPIP-NEO & Open./Liberalism & - \\
\hline Believe in one true religion. & -.19 & -.20 & -.17 & IPIP-NEO & Open./Liberalism & - \\
\hline Like to stand during the national anthem. & -.18 & -.20 & -.17 & IPIP-NEO & Open./Liberalism & - \\
\hline People should always respect the law. & -.18 & -.19 & -.16 & SAPA-EPQ & Psychoticism & - \\
\hline Believe that we coddle criminals too much. & -.17 & -.18 & -.15 & IPIP-NEO & Open./Liberalism & - \\
\hline Tend to vote for liberal political candidates. & .17 & .15 & .18 & IPIP-NEO & Open./Liberalism & + \\
\hline See myself as an average person. & -.15 & -.17 & -.14 & IPIP-HEXACO & Hon./Modesty & + \\
\hline Believe that I am better than others. & .15 & 14 & .17 & IPIP-NEO & Agr./Modesty & - \\
\hline Break rules. & .15 & 13 & .17 & IPIP-NEO & Con./Dutifulness & - \\
\hline Stick to the rules. & -.15 & -.16 & -.14 & IPIP-NEO & Agr./Morality & + \\
\hline Don't consider myself religious. & .15 & 13 & .17 & IPIP-MPQ & Traditionalism & - \\
\hline Believe that we should be tough on crime. & -.15 & -.16 & -.13 & IPIP-NEO & Open./Liberalism & - \\
\hline Cannot imagine lying or cheating. & -.15 & -.16 & -.13 & IPIP-QB6 & Honesty-Propriety & + \\
\hline Like to arrive at appointments in plenty of time. & -.15 & -.16 & -.13 & SAPA-EPQ & Psychoticism & - \\
\hline Think of others first. & -.14 & -.15 & -.12 & IPIP-BFFM & Agreeableness & + \\
\hline Admire a really clever scam. & .14 & .12 & .15 & IPIP-HEXACO & Hon./Fairness & - \\
\hline Dislike routine. & .13 & .12 & .15 & BFAS & Con./Orderliness & - \\
\hline Don't think that I'm better than other people. & -.13 & -.15 & -.12 & IPIP-HEXACO & Hon./Modesty & + \\
\hline Respect authority. & -.13 & -.15 & -.12 & BFAS & Agr./Politeness & + \\
\hline Would never cheat on my taxes. & -.13 & -.14 & -.11 & IPIP-NEO & Agr./Morality & + \\
\hline See that rules are observed. & -.13 & -.14 & -.11 & BFAS & Con./Orderliness & + \\
\hline
\end{tabular}

${ }^{*}$ Open. $=$ Openness; Hon. $=$ Honesty-Humility; Agr. = Agreeableness; Con. = Conscientiousness

For population density, the average training multiple correlation was $R=.38$ and the average validation correlation was $R=.33$. There were 21 personality items selected. In the full sample, a best-items scale made up of these items had a moderate correlation with population density $(R=.38)$. The items in the best-items scale for population density were conceptually consistent and indicated that the personality of residents in densely populated ZIP Codes included: politically liberal, areligious, and anti-authoritarian attitudes; low concern for abiding by rules, laws, and routines; and beliefs of self-exceptionalism (Table 2). Six of ten Liberalism items were in this best-items scale, suggesting that the relationship between Liberalism and population density was not due to just a few items. However, no other facet was as well-represented. Additionally, there was one instance where items with similar content were represented by seemingly different traits. A theme of aversion to rules was represented by items from five different scales: Dutifulness ("Break rules"), Morality ("Stick to the rules"), Orderliness ("See that rules are observed"), 
Table 3: The 18 personality items most highly correlated with ZIP Code income disparity. The column "Corr." is a mean of 1,000 zero-order correlations, each using a random $90 \%$ sample. Lower and upper confidence intervals are \pm 2 SDs based upon the 1,000 iterations. The column "Key" indicates whether the item was positively or negatively keyed on the listed domain/facet. Some items may appear in more than one inventory.

\begin{tabular}{|c|c|c|c|c|c|c|}
\hline Personality item & Corr. & Lower & Upper & Inventory & Domain/Facet* & Key \\
\hline Tend to vote for liberal political candidates. & .23 & .21 & .25 & IPIP-NEO & Open./Liberalism & + \\
\hline Respect authority. & -.20 & -.21 & -.18 & BFAS & Agr./Politeness & + \\
\hline $\begin{array}{l}\text { Believe that criminals should receive help } \\
\text { rather than punishment. }\end{array}$ & .18 & .16 & .20 & IPIP-NEO & Open./Liberalism & + \\
\hline Like to stand during the national anthem. & -.17 & -.19 & -.15 & IPIP-NEO & Open./Liberalism & - \\
\hline Know that anyone who tries can get a job. & -.17 & -.19 & -.15 & IPIP-MPQ & Unlikely virtues & + \\
\hline See myself as an average person. & -.17 & -.18 & -.15 & IPIP-HEXACO & Hon./Modesty & + \\
\hline Believe that I am better than others. & .17 & .15 & .18 & IPIP-NEO & Agr./Modesty & - \\
\hline People should always respect the law. & -.17 & -.18 & -.15 & SAPA-EPQ & Psychoticism & - \\
\hline Believe that we coddle criminals too much. & -.16 & -.18 & -.15 & IPIP-NEO & Open./Liberalism & - \\
\hline Believe in one true religion. & -.16 & -.18 & -.15 & IPIP-NEO & Open./Liberalism & - \\
\hline Try to avoid complex people. & -.15 & -.16 & -.13 & IPIP-BFFM & Intellect & - \\
\hline Don't consider myself religious. & .14 & .13 & 16 & IPIP-MPQ & Traditionalism & - \\
\hline Avoid difficult reading material. & -.14 & -.16 & -.13 & IPIP-NEO & Open./Intellect & - \\
\hline Find political discussions interesting. & .14 & .13 & .16 & IPIP-HEXACO & Open./Inquisitiveness & + \\
\hline Believe that we should be tough on crime. & -.14 & -.16 & -.13 & IPIP-NEO & Open./Liberalism & - \\
\hline Avoid philosophical discussions. & -.14 & -.16 & -.13 & IPIP-NEO & Open./Intellect & - \\
\hline Admire a really clever scam. & .14 & .13 & 16 & IPIP-HEXACO & Hon./Fairness & - \\
\hline Stick to the rules. & -.14 & -.15 & -.13 & IPIP-NEO & Agr./Morality & + \\
\hline
\end{tabular}

Honesty-Propriety ("Cannot imagine lying or cheating"), and Psychoticism ("People should always respect the law").

For income disparity, the average training multiple correlation was $R=.39$ and the average validation correlation was $R=.35$. There were 18 personality items selected. In the full sample, a best-items scale made up of these items had a moderate correlation with income disparity $(R=$ .42). The items in the best-items scale for income disparity were conceptually consistent and indicated that the personality of residents in income disparate ZIP Codes included: politically liberal, areligious, and anti-authoritarian attitudes; intellectual interests; low concern for abiding by rules and laws; and beliefs of self-exceptionalism (Table 3). Six of ten Liberalism items were in this best-items scale, suggesting that the relationship between Liberalism and income disparity was not due to just a few items. Although no other facet was as well represented, there was a common theme of intellectual interests among three similar scales: the Intellect domain ("Try to avoid complex people"), the Intellect facet ("Avoid difficult reading material"), and the Inquisitiveness 
facet ("Find political discussions interesting"). Twelve of the items in the empirical scale for income disparity were also in the best-items personality scale for population density, and differences in the mismatching items indicated that residents in densely populated ZIP Codes were unique in having low concern for routines, whereas residents in income disparate ZIP Codes were unique in their intellectual interests.

For median income, the average training multiple correlation was $R=.22$ and the average validation correlation was $R=.14$. Only one personality item, "Believe that I am better than others," was selected. Because one item was not sufficient to create a personality scale, best-items scale analysis was terminated for median income. For ethnic diversity, the average training multiple correlation was $R=.21$ and the average validation correlation was $R=.14$. Only two personality items, "Am an extraordinary person" and "Need the approval of others," were selected. Because two items were not sufficient to create a personality scale, best-items scale analysis was terminated for ethnic diversity.

Multiple regression model comparison with personality nuances, facets, and domains

To compare how strongly ZIP Code population density and income disparity were related to personality at the nuance, facet, and domain levels, we created three linear regression models for each criterion, with each model using a different level of personality. ${ }^{8}$ The models used only ZIP Code-level data (i.e., in multilevel modeling terminology, only level 2 data). We did not include median income or ethnic diversity in these analyses because the previous null results indicated that a best-items scale could not be generated for these two demographics. For ZIP Code population density, regression models built with nuances (Model 1) and facets (Model 2) accounted for approximately the same amount of variance $\left(R^{2}=.14\right.$ ), while the Big Five (Model 3) accounted for slightly less $\left(R^{2}=.12\right)$, despite differences in the number of personality items used in each model $(k=21,60$, and 180, respectively; Table 4). For ZIP Code income disparity, variance accounted for was largest for the regression model built with nuances (Model $1 ; R^{2}=.18$ ), was slightly less for facets (Model 2; $R^{2}=.17$ ), and was even less for the Big Five (Model $3 ; R^{2}=.14$ ), despite

\footnotetext{
${ }^{8}$ ZIP Codes varied by participant demographics: educational attainment, parents' education, average age, gender ratio, and percentage with minority status. For regression models that include those variables as covariates, see Tables 6 and 7 of the supplemental materials.
} 
differences in the number of personality items used in each $(k=18,70$, and 180, respectively; Table $5)$.

Table 4: Regression models accounting for variance in ZIP Code population density: $\beta$ coefficients for personality variables. The column "Corr." lists zero-order correlations with population density. The number of personality items used in a given model is listed. Standard errors are small for all $\beta$ coefficients in all models $(.02 \leq S E \leq .03)$; the unadjusted minimum significant $|\beta|=.04(\mathrm{p}<$ $.05)$.

\begin{tabular}{lrrrr}
\hline Variable & Corr. & $\begin{array}{r}\text { Model 1 } \\
\text { 21 items }\end{array}$ & $\begin{array}{r}\text { Model 2 } \\
\text { 60 items }\end{array}$ & $\begin{array}{r}\text { Model 3 } \\
\text { 180 items }\end{array}$ \\
\hline Best-items scale & .38 & .38 & - & - \\
O5: Intellect & .24 & - & .14 & - \\
O6: Liberalism & .27 & - & .16 & - \\
C3: Dutifulness & -.17 & - & -.06 & - \\
C5: Self-discipline & -.19 & - & -.08 & - \\
A2: Morality & -.19 & - & -.07 & - \\
A5: Modesty & -.19 & - & -.11 & - \\
Openness & .28 & - & - & .25 \\
Conscientiousness & -.17 & - & - & -.07 \\
Agreeableness & -.21 & - & - & -.17 \\
Multiple R & - & .38 & .37 & .35 \\
$R^{2}$ & - & .14 & .14 & .12 \\
\hline
\end{tabular}


Table 5: Regression models accounting for variance in ZIP Code income disparity: $\beta$ coefficients for personality variables. The column "Corr." lists zero-order correlations with income disparity. The number of personality items used in a given model is listed. Standard errors are small for all $\beta$ coefficients in all models $(.02 \leq S E \leq .03)$; the unadjusted minimum significant $|\beta|=.04(\mathrm{p}<$ $.05)$.

\begin{tabular}{lrrrr}
\hline Variable & Corr. & $\begin{array}{r}\text { Model 1 } \\
\text { 18 items }\end{array}$ & $\begin{array}{r}\text { Model 2 } \\
\text { 70 items }\end{array}$ & $\begin{array}{r}\text { Model 3 } \\
\text { 180 items }\end{array}$ \\
\hline Best-items scale & .42 & .42 & - & - \\
O5: Intellect & .28 & - & .17 & - \\
O6: Liberalism & .30 & - & .17 & - \\
C2: Orderliness & -.19 & - & -.04 & - \\
C3: Dutifulness & -.18 & - & -.05 & - \\
C5: Self-discipline & -.25 & - & -.13 & - \\
A2: Morality & -.19 & - & -.05 & - \\
A5: Modesty & -.18 & - & -.08 & - \\
Openness & .31 & - & - & .27 \\
Conscientiousness & -.23 & - & - & -.14 \\
Agreeableness & -.19 & - & - & -.13 \\
Multiple R & - & .42 & .41 & .38 \\
$R^{2}$ & - & .18 & .17 & .14 \\
\hline
\end{tabular}

Discussion

ZIP Codes were better than states as units of aggregated personality. Participants were found to be clustered in ZIP Codes by personality. Consistent with our hypothesis, this clustering effect was 4.4 times as large for U.S. ZIP Code residence than for U.S. state residence. In terms of aggregating individual personality in this sample, ZIP Codes were a better geographic unit than states. This finding suggests that in addition to being a relevant unit of geographical psychology, ZIP Codes may better cluster individual personality than larger geographic regions within a country.

ZIP Code demographics were systematically related to aggregated personality. Population density and income disparity were found to be positively correlated with Openness and negatively correlated with Conscientiousness and Agreeableness, which was consistent with two previous studies (Jokela et al., 2015; de Vries, Gosling, \& Potter, 2011). Neither Openness nor Conscientiousness was notably correlated with ethnic diversity, and Extraversion was not correlated with population density, which was inconsistent with a previous study (Jokela et al., 2015). This inconsistency 
across studies may be explained by the fact that the previous study examined the postal districts of London, whereas the current study examined ZIP Codes from all across the United States. Certain ZIP Code demographics, such as ethnic diversity, may exhibit systematic relationships with aggregated personality within a city but not across cities, per the Yule-Simpson paradox (Yule, 1903; Simpson, 1951; Kievit, Frankenhuis, Waldorp, \& Borsboom, 2013).

Compared to domains, facets provided more specificity concerning the relationships between demographics and personality. Facets within the Big Five domains of Openness, Conscientiousness, and Agreeableness were differentially correlated with population density and income disparity. Specifically, six or seven facets were most responsible for these relationships between personality and the two demographics: Intellect, Liberalism, Dutifulness, Self-discipline, Morality, Modesty, and (only for income disparity) Orderliness. Liberalism's positive correlation with population density was consistent with a previous study (Tausanovitch \& Warshaw, 2014), while Liberalism's lack of positive correlation with ethnic diversity (Figure 8 of the supplemental materials) was inconsistent with a previous study (Pew Research Center, 2014). This inconsistency across studies may be due to differences in studies; the previous study measured self-identified liberals' preference for a neighborhood's ethnic diversity, whereas the current study measured the extent to which ZIP Codes higher in Liberalism were also ethnically diverse.

\section{Compared to facets, nuances provided more specificity concerning the relationships between} demographics and personality. The personality items that correlated most strongly with population density or income disparity provided a precise description of the personality-demographic relationships. Although the two sets of items were not completely identical, descriptive summaries of each set of items were similar: compared to residents of sparse and equal-income ZIP Codes, residents of densely populated and income disparate ZIP Codes tended to have more politically liberal, areligious, and anti-authoritarian attitudes; lower concern for abiding by rules and laws; and greater beliefs of self-exceptionalism. Residents of densely populated ZIP Codes also showed lower concern for routines, while residents of income disparate neighborhoods reported more intellectual interests. The best-items scale for population density had a moderate correlation with population density $(R=.38)$, as did the best-items scale for income disparity with income disparity $(R=.42)$. 
The accuracy of models using a small subset of nuances was as good or slightly better than that of models that used facets or domains. We compared the variance explained for population density and income disparity across the three levels of personality (nuances, facets, and domains), using multiple regression models. In the case of population density, nuances and facets explained the same amount of variance $\left(R^{2}=.14\right)$, while domains explained slightly less $\left(R^{2}=.12\right)$. In the case of income disparity, nuances $\left(R^{2}=.18\right)$ explained slightly more than facets $\left(R^{2}=.17\right)$, which explained more than domains $\left(R^{2}=.14\right)$. Previous research has found that models utilizing nuances are substantially more predictive of outcomes than domains or facets, but these nuance-level models have utilized all of the items in an item pool (Seeboth \& Mõttus, 2018; Mõttus et al., 2015; Mõttus, Bates, et al., 2018). The predictive utility of nuances may have been underestimated in this study due to the approach of retaining a small subset of the items that most highly correlated with a demographic.

\section{Nuance-level specificity may help generate better-informed personality theory}

Facet-level analysis may help guide psychological research away from overgeneralizations that would have been difficult to avoid with domain-level analysis. If the current study were to have examined the relationship between Openness and population density only at the domain level, the theory generated to explain the existence of these results might have relied on the domain of Openness as a whole. We even might have conjured an image of residents that would have relied more on a few facets that weren't actually as important, such as free-spirited bohemians or imaginative artists. Instead, the current study narrowed the personality traits of interest from 18 facets (contained within three domains) to just six or seven facets.

Nuance-level analysis described an even more precise personality pattern, indicating that residents of densely populated and income disparate ZIP Codes tended to have more politically liberal beliefs, more anti-authoritarian attitudes, a stronger aversion to rules, and greater beliefs of selfexceptionalism. Conversely, residents of more sparsely populated and equal-income ZIP Codes typically were more politically conservative, authoritarian, and believing in the rule of law. The broader facet-level analysis identified Dutifulness, Morality, and Orderliness as being associated with population density, whereas nuance-level descriptive analysis indicated that nuances from five 
different traits (Dutifulness, Morality, Orderliness, Honesty-Propriety, and Psychoticism) were correlated with population density, and these nuances all clustered around the theme of aversion to rules. A qualitative interpretation of the nuance-level results is that the three identified facets were not uniquely important, but instead only appeared to be related to population density because all three contained items related to aversion to rules. Thus, a more precise description of the relationship between ZIP Code population density and personality would ignore the broader facets of Dutifulness, Morality, and Orderliness and instead focus on nuances related to aversion to rules, which themselves may indicate a novel facet-sized trait. By contrast, there was strong evidence that the whole facet of Liberalism was positively associated with population density and income disparity; six of ten Liberalism items were present in each demographic's best-items scale.

A similar pattern of nuances was found in the best items for ZIP Code population density and income disparity, which could indicate a common underlying personality pattern (political orientation, views on authoritarianism, beliefs concerning the importance of rules and how rules apply to oneself) that is related to both demographic variables. This pattern of nuances is consistent with prior research that has linked population density with antisocial personality traits (Jonason, 2018), and income inequality with crime (Wilson \& Daly, 1997; Daly et al., 2001; Rufrancos et al., 2013), disinvestment in social capital (Kawachi et al., 1997), risk-taking (Payne, Brown-Iannuzzi, \& Hannay, 2017), and support for liberal policies (Brown-Iannuzzi, Lundberg, Kay, \& Payne, 2014).

Plausible mechanisms for the personality-demographic relationships in this study

Each of the three broad hypotheses concerning how relationships between aggregated personality and demographics form (environmental factors, migration choices, and social influence) is plausible for explaining why personality aggregated by ZIP Code was related to population density and income disparity in this study. For example, ZIP Code population density and income disparity may act like environmental factors such that they affect residents' beliefs concerning politics, authority, and rules. Living in close proximity to others who are vastly wealthier may lead residents to become more averse to laws, rules, and authority figures that appear to reinforce that inequality. Alternatively, individuals who migrate to densely populated or income disparate ZIP Codes may be more willing to live in actual or perceived higher-crime areas because of their particular beliefs and 
behaviors that deemphasize the importance of rules, punishment, and authority figures. Conversely, residents of less dense or more equal-income ZIP Codes may seek the safety of lower crime ZIP Codes because they prefer a stronger authoritarian presence and the enforcement of rules and laws through punishment. Additionally, personality-typical residents of a ZIP Code may socially influence new residents toward the prevailing thoughts, feelings, behaviors, and beliefs of the ZIP Code. Lastly, all three of these explanations may be partially responsible for the personalitydemographic relationships.

\section{Limitations}

One limitation of this study was the relatively low number of participants per ZIP Code (mean $=19.2$, median $=14)$, which led to low reliabilities at the ZIP Code-level of analysis. However, we found that the correlational structure of the data was robust to increases in the number of participants per ZIP Code. For a future study to reach high ZIP Code reliability of personality variables, a very large sample would be needed. For example, if one assumed that ZIP Code residence would explain $2 \%$ of personality variance and they desired an ICC2 reliability of .80, an average of 196 participants per ZIP Code would be needed, requiring a sample roughly ten times as large as the current study.

A second limitation of this study was that ZIP Codes were perhaps less ideal units of geographical psychology than neighborhoods. ZIP Codes were created by the U.S. Post Office for efficient mail delivery, not for demarcating small communities or neighborhoods (U.S. Postal Service Office of Inspector General, 2013). A ZIP Code can cover an area larger than a neighborhood, sometimes an entire town (e.g., Sand Springs, Oklahoma, 74063). Ideally, a geographical psychology study would utilize even smaller standardized geographic units that are closer in size to neighborhoods, such as census tracts. However, there are at least two disadvantages of studying census tracts. First, U.S. residents know the ZIP Code in which they live, while few are aware of their census tract. Thus it would be necessary to ask participants to share their home addresses. Some individuals may not be willing to share this information due to privacy concerns. Second, compared to the ZIP Code, a geographic unit as small as a census tract would require even more participants to achieve an acceptable number of participants-per-unit. Thus, millions of participants could be 
required.

\section{Constraints on generality}

In accordance with recommendations by Simons, Shoda, \& Lindsay (2017), we acknowledge the following constraints on generality. One constraint concerns sample representativeness. Although the sample was ethnically diverse, participants tended to be more educated than the U.S. population. Thus, it is likely that this study undersampled individuals of lower socioeconomic status. In general, online samples are not representative of the U.S. population, but tend to be more diverse than traditional samples from psychological research (Gosling, Vazire, Srivastava, \& John, 2004). We expect our findings to replicate in other large samples collected by personality psychologists, but a truly representative sample of the U.S. could show different results regarding ZIP Code personality-demographic relationships. We expect for personality to cluster by U.S. ZIP Codes, and for this effect to be stronger than for U.S. states, so long as the new sample is at least as diverse as the current one. Both clustering effects may be stronger in a more representative sample due to the current sample having a somewhat restricted range (specifically in terms of educational attainment). We expect for our results to generalize to a measure of neighborhoods (e.g., U.S. census tracts), but perhaps not geographic units as large as U.S. states, since a state-wide measure of population density would not accurately capture the density of cities or rural areas within the state. As our data were self-reported, we expect our results to generalize to self-reported measures of personality. Although we performed sensitivity analyses to determine the extent to which results were robust against including more or fewer ZIP Codes, substantially diverging from the number of ZIP Codes in this study (either more or fewer) could impact the extent to which these results will replicate in a new study. In particular, the results of this study may not generalize to an examination of ZIP Code personality-demographic relationships within a single metropolitan area. A replication of our nuance-level results would require a large pool of items from multiple inventories. We have no reason to believe that the results depend on other characteristics of the participants, materials, or context. 
Future directions

Future studies in all branches of personality psychology could benefit from examining the extent to which facet- and nuance-level analyses provide greater specificity to domain-level findings, as long as researchers have the resources to collect a large sample of participants and randomly sample from an item pool of hundreds of items. Narrowing the unit of personality analysis has the potential to help guide new theories away from overgeneralizations that are easily committed when only using domain-level data. The field of geographical psychology may benefit from determining whether smaller units of analysis always provide better clustering of personality or whether there is an optimal unit of analysis, such as ZIP Codes or census tracts. It would also be valuable to determine the extent to which postal codes or neighborhoods are comparable across cities, and whether the comparison of personality aggregated by postal codes is more appropriate within a city than across cities.

\section{Conclusion}

This study presented evidence that smaller units of analysis were better, both for geographical and personality psychology. For geographical psychology, the personality variance explained was four times as large for U.S. ZIP Codes than for U.S. states. For personality psychology, facets provided more specificity than domains concerning personality-demographic relationships, and nuances provided even more specificity than facets. This study found that ZIP Code population density and income disparity were positively correlated with a pattern of nuances that included an aversion to rules, political liberalism, anti-authoritarianism, and self-exceptionalism. While this finding is informative in itself, it also illustrates the utility of facet- and nuance-level analyses in large samples. Domains like the Big Five describe, by definition, broad generalizations concerning personality. Facet- and nuance-level approaches reveal more informative patterns of how personality is systematically related to our world.

\section{References}

Achaa-Amankwaa, P., Olaru, G., \& Schroeders, U. (2020). Coffee or Tea? Examining Cross-Cultural Differences in Personality Nuances Across Former Colonies of the British Empire. https://psyarxiv.com/dpqrx/. 
Alabama State Data Center. (2012). 2010 Census. Retrieved from https://www.census.gov/programs -surveys/decennial-census/data/datasets.2010.html

Alabama State Data Center. (2015). ZIP Code Tabulation Areas reference page. Retrieved from https:// www. census.gov/geo/reference/zctas.html

Alabama State Data Center. (2017). Archived page on ZIP Code Tabulation Areas. Retrieved from https:// cber.cba.ua.edu/asdc/zip_zcta.html

American Academy of Family Physicians. (2017). ZIP Code to ZCTA Crosswalk. Retrieved from https:// www. udsmapper.org/zcta-crosswalk.cfm

Bacolod, M., Blum, B. S., \& Strange, W. C. (2009). Skills in the city. Journal of Urban Economics, 65(2), 136-153. doi: 10.1016/j.jue.2008.09.003

Bleidorn, W., Schonbrodt, F., Gebauer, J. E., Rentfrow, P. J., Potter, J., \& Gosling, S. D. (2016). To live among like-minded others: Exploring the links between person-city personality fit and self-esteem. Psychological Science, 27(3), 419-427. doi: 10.1177/0956797615627133

Bliese, P. D. (2000). Within-group agreement, non-independence, and reliability: Implications for data aggregation and analysis. In K. J. Klein \& S. W. J. Kozlowski (Eds.), Multilevel theory, research, and methods in organizations: foundations, extensions, and new directions. (pp. 349-381). San Francisco, CA: Jossey-Bass.

Breiman, L. (1996). Bagging Predictors. Machine Learning, 24(2), 123-140. doi: 10.1007/BF00058655

Brown-Iannuzzi, J. L., Lundberg, K. B., Kay, A. C., \& Payne, K. (2014). Subjective Status Shapes Political Preferences. Psychological Science, 26(1), 15-26. doi: 10.1177/0956797614553947

Ceriani, L., \& Verme, P. (2011). The origins of the Gini index: Extracts from Variabilità e Mutabilità (1912) by Corrado Gini. The Journal of Economic Inequality, 10(3), 421-443. doi: 10.1007/s10888-011-9188-x

Chapman, B. P., Weiss, A., \& Duberstein, P. R. (2016). Statistical learning theory for high dimensional prediction: Application to criterion-keyed scale development. Psychological Methods, 21(4), 603-620. doi: $10.1037 / \operatorname{met} 0000088$

Condon, D. M., \& Revelle, W. (2015a). Selected personality data from the SAPA-Project: 08Dec2013 to 26Jul2014. Harvard Dataverse. Retrieved from https://doi.org/10.7910/DVN/SD7SVE 
Condon, D. M., \& Revelle, W. (2015b). Selected personality data from the SAPA-Project: On the structure of phrased self-report items. Journal of Open Psychology Data, 3(6). doi: 10.5334/jopd.al

Condon, D. M., \& Revelle, W. (2018). Selected personality data from the SAPA-Project: 18 aug2010 to 08dec2013. Harvard Dataverse. Retrieved from https://doi.org/10.7910/DVN/C40K1U

Condon, D. M., Roney, E., \& Revelle, W. (2017a). A SAPA Project Update: On the Structure of phrased Self-Report Personality Items. Journal of Open Psychology Data, 5(1). doi: 10.5334/jopd.32

Condon, D. M., Roney, E., \& Revelle, W. (2017b). Selected personality data from the SAPA-Project: 22Dec2015 to 07Feb2017. Harvard Dataverse. Retrieved from https://doi.org/10.7910/DVN/TZJGAT

Condon, D. M., Roney, E., \& Revelle, W. (2017c). Selected personality data from the SAPA-Project: 26Jul2014 to 22Dec2015. Harvard Dataverse. Retrieved from https://doi.org/10.7910/DVN/GU70EV

Costa, P. T., \& McCrae, R. R. (1992). Revised NEO Personality Inventory (NEO PI-R) and NEO Five-factor Inventory (NEO-FFI) professional manual. Psychological Assessment Resources. Odessa, FL.

Daly, M., Wilson, M., \& Vasdev, S. (2001). Income inequality and homicide rates in Canada and the United States. Canadian Journal of Criminology, 43(2), 219-236.

de Vries, R., Gosling, S., \& Potter, J. (2011). Income inequality and personality: Are less equal US states less agreeable? Social Science \& Medicine, 72(12), 1978-1985. doi: 10.1016/j.socscimed.2011.03.046

Dunn, O. J. (1961). Multiple comparisons among means. Journal of the American Statistical Association, 56, 52-64. doi: $10.2307 / 2282330$

Easterly, W., \& Levine, R. (1997). Africa's growth tragedy: Policies and ethnic divisions. The Quarterly Journal of Economics, 112(4), 1203-1250. doi: 10.1162/003355300555466

Elleman, L. G., Condon, D. M., McDougald, S. K., \& Revelle, W. (in press). That takes the BISCUIT: Predictive accuracy and parsimony of four statistical learning techniques in personality data, with data missingness conditions. European Journal of Psychological Assessment.

Elleman, L. G., Condon, D. M., Russin, S. E., \& Revelle, W. (2018). The personality of U.S. states: Stability from 1999 to 2015. Journal of Research in Personality, 72, 64-72. doi: 10.1016/j.jrp.2016.06.022

Frank, R. H. (2013). Falling behind: How rising inequality harms the middle class. Berkeley, CA: University of California Press. 
Gimpel, J. G., \& Hui, I. S. (2015). Seeking politically compatible neighbors? The role of neighborhood partisan composition in residential sorting. Political Geography, 48, 130-142. doi: 10.1016/j.polgeo.2014 .11 .003

Glaeser, E. L., \& Maré, D. C. (2001). Cities and skills. Journal of Labor Economics, 19(2), 316-342. doi: $10.3386 / \mathrm{w} 4728$

Goldberg, L. R. (1999). A broad-bandwidth, public domain, personality inventory measuring the lowerlevel facets of several five-factor models. In I. Mervielde, I. Deary, F. De Fruyt, \& F. Ostendorf (Eds.), Personality psychology in europe (pp. 7-28). Tilburg, Netherlands: Tilburg University Press.

Goldberg, L. R., Johnson, J. A., Eber, H. W., Hogan, R., Ashton, M. C., Cloninger, C. R., \& Gough, H. G. (2006). The international personality item pool and the future of public-domain personality measures. Journal of Research in Personality, 40(1), 84-96. doi: 10.1016/j.jrp.2005.08.007

Gosling, S. D., Vazire, S., Srivastava, S., \& John, O. P. (2004). Should we trust web-based studies? A comparative analysis of six preconceptions about internet questionnaires. American Psychologist, 59(2), 93-104. doi: 10.1037/0003-066X.59.2.93

Hathaway, S. R., \& McKinley, J. C. (1942). Manual for the Minnesota Multiphasic Personality Inventory. Minneapolis, MN: University of Minnesota Press.

Holm, S. (1979). A simple sequentially rejective multiple test procedure. Scandinavian Journal of Statistics, 6(2), 65-70. doi: $10.2307 / 4615733$

Jokela, M. (2014). Flow of cognitive capital across rural and urban United States. Intelligence, 46, 47-53. doi: 10.1016/j.intell.2014.05.003

Jokela, M., Bleidorn, W., Lamb, M. E., Gosling, S. D., \& Rentfrow, P. J. (2015). Geographically varying associations between personality and life satisfaction in the London metropolitan area. Proceedings of the National Academy of Sciences, 112(3), 725-730. doi: 10.1073/pnas.1415800112

Jonason, P. K. (2018). Bright lights, big city: The Dark Triad traits and geographical preferences. Personality and Individual Differences, 132, 66-73. doi: 10.1016/j.paid.2018.05.024

Kawachi, I., Kennedy, B. P., Lochner, K., \& Prothrow-Stith, D. (1997). Social capital, income inequality, and mortality. American Journal of Public Health, 87(9), 1491-1498. doi: 10.2105/ajph.87.9.1491 
Kievit, R. A., Frankenhuis, W. E., Waldorp, L. J., \& Borsboom, D. (2013). Simpson's paradox in psychological science: A practical guide. Frontiers in Psychology, 4(513). doi: 10.3389/fpsyg.2013.00513

Leventhal, T., \& Brooks-Gunn, J. (2000). The neighborhoods they live in: The effects of neighborhood residence on child and adolescent outcomes. Psychological Bulletin, 126(2), 309-337. doi: 10.1037// 0033-2909.126.2.309

Little, T. D., Jorgensen, T. D., Lang, K. M., \& Moore, E. W. G. (2013). On the Joys of Missing Data. Journal of Pediatric Psychology, 151-162. doi: 10.1093/jpepsy/jst048

McCrae, R. R. (2015). A More Nuanced View of Reliability: Specificity in the Trait Hierarchy. Personality and Social Psychology Review, 19(2), 97-112. doi: 10.1177/1088868314541857

McCrae, R. R., \& Terracciano, A. (2008). The Five-Factor Model and its correlates in individuals and cultures. In F. J. R. van der Vijver, D. A. van Hemert, \& Y. H. Poortinga (Eds.), Multilevel analysis of individuals and cultures (pp. 249-283). New York, NY: Taylor \& Francis Group/Lawrence Erlbaum Associates.

Mershon, B., \& Gorsuch, R. L. (1988). Number of factors in the personality sphere: Does increase in factors increase predictability of real-life criteria? Journal of Personality and Social Psychology, 55(4), 675-680. doi: $10.1037 / 0022-3514.55 .4 .675$

Morrill, R., Knopp, L., \& Brown, M. (2007). Anomalies in red and blue: Exceptionalism in American electoral geography. Political Geography, 26(5), 525-553. doi: 10.1016/j.polgeo.2007.03.006

Mõttus, R., Bates, T. C., Condon, D. M., Mroczek, D. K., \& Revelle, W. (2018). Leveraging a more nuanced view of personality: Narrow characteristics predict and explain variance in life outcomes. https://psyarxiv.com/4q9gv/.

Mõttus, R., Kandler, C., Bleidorn, W., Riemann, R., \& McCrae, R. R. (2017). Personality Traits Below Facets: The Consensual Validity, Longitudinal Stability, Heritability, and Utility of Personality Nuances. Journal of Personality and Social Psychology, 112(3), 474-490. doi: 10.1037/pspp0000100

Mõttus, R., McCrae, R. R., Allik, J., \& Realo, A. (2014). Cross-rater agreement on common and specific variance of personality scales and items. Journal of Research in Personality, 52, 47-54. doi: 10.1016/ j.jrp.2014.07.005 
Mõttus, R., Realo, A., Allik, J., Esko, T., \& Metspalu, A. (2012). History of the diagnosis of a sexually transmitted disease is linked to normal variation in personality traits. The Journal of Sexual Medicine, 9(11), 2861-2867. doi: 10.1111/j.1743-6109.2012.02891.x

Mõttus, R., Realo, A., Allik, J., Esko, T., Metspalu, A., \& Johnson, W. (2015). Within-Trait Heterogeneity in Age Group Differences in Personality Domains and Facets: Implications for the Development and Coherence of Personality Traits. PLOS ONE, 10(3). doi: 10.1371/journal.pone.0119667

Mõttus, R., Sinick, J., Terracciano, A., Hřebíčková, M., Ando, J., Mortensen, E. L., .. Jang, K. L. (2018). Personality characteristics below facets: A replication and meta-analysis of cross-rater agreement, rankorder stability, heritability, and utility of personality nuances. Journal of Personality and Social Psychology, 1-17. doi: 10.1037/pspp0000202

Motyl, M., Iyer, R., Oishi, S., Trawalter, S., \& Nosek, B. A. (2014). How ideological migration geographically segregates groups. Journal of Experimental Social Psychology, 51, 1-14. doi: 10.1016/j.jesp.2013.10.010

Ozer, D. J., \& Benet-Martínez, V. (2006). Personality and the prediction of consequential outcomes. Annual Review of Psychology, 57(1), 401-421. doi: 10.1146/annurev.psych.57.102904.190127

Park, N., \& Peterson, C. (2010). Does it matter where we live?: The urban psychology of character strengths. American Psychologist, 65(6), 535-547. doi: 10.1037/a0019621

Paunonen, S. V., \& Ashton, M. C. (2001). Big five factors and facets and the prediction of behavior. Journal of Personality and Social Psychology, 81 (3), 524-539. doi: 10.1037/0022-3514.81.3.524

Paunonen, S. V., Haddock, G., Forsterling, F., \& Keinonen, M. (2003). Broad versus narrow personality measures and the prediction of behaviour across cultures. European Journal of Personality, 17(6), 413433. doi: $10.1002 /$ per.496

Payne, K. (2017). The Broken ladder: How inequality affects the way we think, live, and die. New York, NY: Viking.

Payne, K., Brown-Iannuzzi, J. L., \& Hannay, J. W. (2017). Economic inequality increases risk taking. Proceedings of the National Academy of Sciences, 114(18), 4643-4648. doi: 10.1073/pnas.1616453114

Pesta, B. J., Bertsch, S., McDaniel, M. A., Mahoney, C. B., \& Poznanski, P. J. (2012). Differential epidemiology: IQ, neuroticism, and chronic disease by the 50 U.S. states. Intelligence, 40(2), 107-114. doi: 10.1016/j.intell.2012.01.011 
Pew Research Center. (2014). Political Polarization in the American Public. Retrieved from http:// www .people-press.org/2014/06/12/political-polarization-in-the-american-public/

Pickett, K. E., \& Wilkinson, R. G. (2015). Income inequality and health: A causal review. Social Science E Medicine, 128(C), 316-326. doi: 10.1016/j.socscimed.2014.12.031

R Core Team. (2018). R: A language and environment for statistical computing [Computer software manual]. Vienna, Austria. Retrieved from https://www.R-project.org/

Rentfrow, P. J. (2010). Statewide differences in personality: Toward a psychological geography of the United States. American Psychologist, 65(6), 548-558.

Rentfrow, P. J. (2014). Geographical differences in personality. In Geographical psychology: Exploring the interaction of environment and behavior. Washington, DC, US: American Psychological Association.

Rentfrow, P. J., Gosling, S. D., Jokela, M., \& Stillwell, D. J. (2013). Divided we stand: Three psychological regions of the United States and their political, economic, social, and health correlates. Journal of Personality and Social Psychology, 105(6), 996-1012. doi: 10.1037/a0034434

Rentfrow, P. J., Gosling, S. D., \& Potter, J. (2008). A theory of the emergence, persistence, and expression of geographic variation in psychological characteristics. Perspectives on Psychological Science, 3(5), 339-369. doi: 10.1111/j.1745-6924.2008.00084.x.

Rentfrow, P. J., \& Jokela, M. (2016). Geographical psychology: The spatial organization of psychological phenomena. Current Directions in Psychological Science, 25(6), 393-398. doi: 10.1177/0963721416658446

Revelle, W. (2020). psych: Procedures for psychological, psychometric, and personality research [Computer software manual]. Evanston, Illinois. Retrieved from https://CRAN.R-project.org/package=psych (R package version 2.0.1)

Revelle, W., Condon, D. M., Wilt, J., French, J. A., Brown, A., \& Elleman, L. G. (2016). Web and phone based data collection using planned missing designs. In N. G. Fielding, R. M. Lee, \& G. Blank (Eds.), Handbook of online research methods. Thousand Oaks, CA: Sage Publications.

Revelle, W., Dworak, E. M., \& Condon, D. M. (2020). Exploring the persome: The power of the item in understanding personality structure. Personality and Individual Differences, 109905. doi: 10.1016/ j.paid.2020.109905 
Revelle, W., Wilt, J., \& Rosenthal, A. (2010). Individual differences in cognition: New methods for examining the personality-cognition link. In Handbook of individual differences in cognition (pp. 27-49). New York, NY: Springer New York.

Roberts, B. W., Kuncel, N., Shiner, R. N., Caspi, A., \& Goldberg, L. (2007). The power of personality: A comparative analysis of the predictive validity of personality traits, SES, and IQ. Perspectives on Psychological Science, 2(4), 313-345. doi: 10.1111/j.1745-6916.2007.00047.x

RStudio Team. (2020). RStudio: Integrated Development Environment for R [Computer software manual]. Boston, MA.

Rufrancos, H., Power, M., Pickett, K. E., \& Wilkinson, R. (2013). Income inequality and crime: A review and explanation of the time-series evidence. Sociology and Criminiology-Open Access, 1(1), 1-9. doi: $10.4172 / 2375-4435.1000103$

Seeboth, A., \& Mõttus, R. (2018). Successful Explanations Start with Accurate Descriptions: Questionnaire Items as Personality Markers for More Accurate Predictions. European Journal of Personality, 32, 186201. doi: $10.1002 /$ per. 2147

Seyle, D. C., \& Newman, M. L. (2006). A house divided? The psychology of red and blue America. American Psychologist, 61(6), 571-580. doi: 10.1037/0003-066X.61.6.571

Shrout, P. E., \& Fleiss, J. L. (1979). Intraclass correlations: Uses in assessing rater reliability. Psychological Bulletin, 86(2), 420-428. doi: 10.1037//0033-2909.86.2.420

Simons, D. J., Shoda, Y., \& Lindsay, D. S. (2017, November). Constraints on Generality (COG): A Proposed Addition to All Empirical Papers. Perspectives on Psychological Science, 12(6), 1123-1128. doi: $10.1177 / 1745691617708630$

Simpson, E. H. (1951). The interpretation of interaction in contingency tables. Journal of the Royal Statistical Society. Series B. Methodological, 13(2), 238-241. doi: 10.1111/j.2517-6161.1951.tb00088.x

Sirgy, M. J., Grzeskowiak, S., \& Su, C. (2005). Explaining housing preference and choice: The role of self-congruity and functional congruity. Journal of Housing and the Built Environment, 20(4), 329-347. doi: $10.1007 / \mathrm{s} 10901-005-9020-7$

Steiger, J. H. (1980). Tests for comparing elements of a correlation matrix. Psychological Bulletin, 87(2), 245-251. doi: 10.1037/0033-2909.87.2.245 
Tausanovitch, C., \& Warshaw, C. (2014). Representation in municipal government. American Political Science Review, 108(3), 605-641. doi: 10.1017/S0003055414000318

Terracciano, A., Sutin, A. R., McCrae, R. R., Deiana, B., Ferrucci, L., Schlessinger, D., .. Costa Jr, P. T. (2009). Facets of Personality Linked to Underweight and Overweight. Psychosomatic Medicine, 71 (6), 682-689. doi: 10.1097/PSY.0b013e3181a2925b

U.S. Census Bureau. (2017). American Community Survey (ACS). Retrieved from https://www.census .gov/programs-surveys/acs/

U.S. Postal Service. (2017). Query: "How many ZIP Codes are there?". Retrieved from http://faq.usps . com/

U.S. Postal Service Office of Inspector General. (2013). The untold story of the ZIP Code. Retrieved from https://www . uspsoig.gov/document/untold-story-zip-code

Vainik, U., Mõttus, R., Allik, J., Esko, T., \& Realo, A. (2015). Are trait-outcome associations caused by scales or particular items? Example analysis of personality facets and BMI. European Journal of Personality, 29(6), 622-634. doi: 10.1002/per.2009

Wickham, H. (2016). ggplot2: Elegant Graphics for Data Analysis. Springer-Verlag New York.

Wilson, M., \& Daly, M. (1997). Life expectancy, economic inequality, homicide, and reproductive timing in Chicago neighbourhoods. British Medical Journal, 314(7089), 1271-1274. doi: 10.1136/bmj.314.7089 .1271

World Bank. (2016). GINI index (World Bank estimate) - United States. Retrieved from https://data .worldbank.org/indicator/SI.POV.GINI?locations=US

Yule, G. U. (1903). Notes on the Theory of Association of Attributes in Statistics. Biometrika, 2(2), 121-134. doi: 10.1093/biomet/2.2.121

\section{Contributions}

Contributed to conception and design: LGE, DMC, NSH, WR.

Contributed to acquisition of data: LGE, DMC, NSH, VRA, WR.

Contributed to analysis and interpretation of data: LGE, WR. 
Drafted and/or revised the article: LGE.

Approved the submitted version for publication: LGE, DMC, NSH, WR.

\section{Funding information}

Preparation of this manuscript was funded in part by grant SMA-1419324 from the National Science Foundation.

\section{Competing interests}

No competing interests exist.

\section{Supplemental materials}

Document SupplementSmallerIsBetter.pdf

Title: Supplemental materials to the article. Four tables and eight figures.

File Type: PDF.

Data accessibility statement

Data and analysis scripts can be found at https://osf.io/fsqyd/. 